\title{
Correction to: Potential distribution of aquatic invasive alien plants, Eichhornia crassipes and Salvinia molesta under climate change in Sri Lanka
}

\author{
Champika S. Kariyawasam (D) - Lalit Kumar (D) Sujith S. Ratnayake $\mathbb{C}$
}

Published online: 28 June 2021

(C) Springer Nature B.V. 2021

Correction to: Wetlands Ecol Manage

https://doi.org/10.1007/s11273-021-09799-4

In the original publication, the ORCID was missed out for corresponding author Champika S. Kariyawasam. The ORCID is updated in this correction.

The original article can be found online at https:// doi.org/10.1007/s11273-021-09799-4.

C. S. Kariyawasam $(\bowtie) \cdot$ L. Kumar · S. S. Ratnayake Ecosystem Management, School of Environmental and Rural Science, University of New England, Armidale, NSW 2351, Australia

e-mail: ckariyaw@myune.edu.au

L. Kumar

e-mail: lkumar@une.edu.au

S. S. Ratnayake

e-mail: rratnay2@myune.edu.au

C. S. Kariyawasam · S. S. Ratnayake

Ministry of Environment and Wildlife Resources,

Battaramulla 10120, Sri Lanka
Publisher's Note Springer Nature remains neutral with regard to jurisdictional claims in published maps and institutional affiliations. 